EUROPEAN HONORS COUNCIL

Note

\title{
Gifted and talented students' academic performance and choices at TU Delft
}

Joanna Daudt ${ }^{1}$

1. Technical University Delft, the Netherlands; Correspondence: J.P.R.B.Daudt@tudelft.nl

Received: 31 January 2017; Accepted: 8 May 2017; Published: 9 May 2017

Keywords: gifted students; Higher Engineering education, honours programmes participation

\section{Introduction}

Since 2009 the department Electrical Engineering, Mathematics and Computer Science at the Technical University (TU) Delft in the Netherlands offers an honours programme to gifted and talented students in the bachelor programmes. The honours programme has a duration of two years and an extra study load of $20 \mathrm{EC}$. Students are selected for this programme when they have completed the first year in the nominal time and have a GPA of 7 or higher (on a scale of 1-10) for the courses in the first year. When students have completed their regular bachelor programme and the extra programme within three years, they receive a TU Delft honours certificate. This honours programme is mainly chosen by students from the bachelor programmes Electrical Engineering or Computer Science. Excellent students (GPA of 8.5 or higher for mathematics and physics at high school) from the bachelor programme Applied Mathematics mostly chose to do a double degree in Applied Mathematics and Applied Physics that involves an extra study load of 35 EC and has no time limit to complete both programmes.

\section{Problem: disappointingly low numbers of honours students}

Although the influx of students is increasing for all regular programmes in recent years, we observed that only a small number of students choose the honours programme and that many of them, after being selected and enrolled, decided to leave the honours programme. Because of these disappointing numbers of excellent and talented students that opted for the honours programme, we have done research into the performance and choices of the ten percent best-performing students (in terms of GPA) coming from secondary education, and among the students that have skipped classes in secondary education ('accelerated students ' or 'early college entrants').

The following research questions were formulated:

- What is the quality of the incoming students from pre-university education ( $v w o$ ) and how many students belong to the subgroup of the top ten percent from vwo and/or to the subgroup of 'accelerated students'?

- What are the academic results of these subgroups in the regular bachelor programme? 
- What choices do these students make in terms of enrichment (honours programme) or extracurricular activities like positions in student associations?

\section{Theoretical framework}

The theoretical framework used in this study is the work of Gagné (2009) to define gifted students, the research of Veenman et al. (Veenman, Bavelaar, De Wolf, \& Van Haaren, 2014) on results from gifted students in secondary schools and their metacognitive skills, and the research of Mendaglio (2013) who describes the effects of "hitting the wall" and "the-bigfish-little pond" that gifted and talented students can meet after their transition from high school to university.

\section{Methods}

The TU Delft student database with data about background (age, grades secondary education), their grades and progress in the first year at TU Delft and time and grades regarding completion of their bachelor programme, has been explored and analysed. With descriptive statistics the students' performance and choices have been clustered for age, GPA, study progress, grades and choices for an honours programme, leadership activities or extra courses. The database was analysed for six cohorts: 2008/2009 till 2014/2015. The choice has been made to focus on students with a Dutch high school diploma who have not switched from another university programme. The top ten percent of these students was chosen based on their GPA in high school. Figure 1 gives an overview of the research population and the subgroups.

Figure 1. Research population, subgroups and distribution per bachelor programme

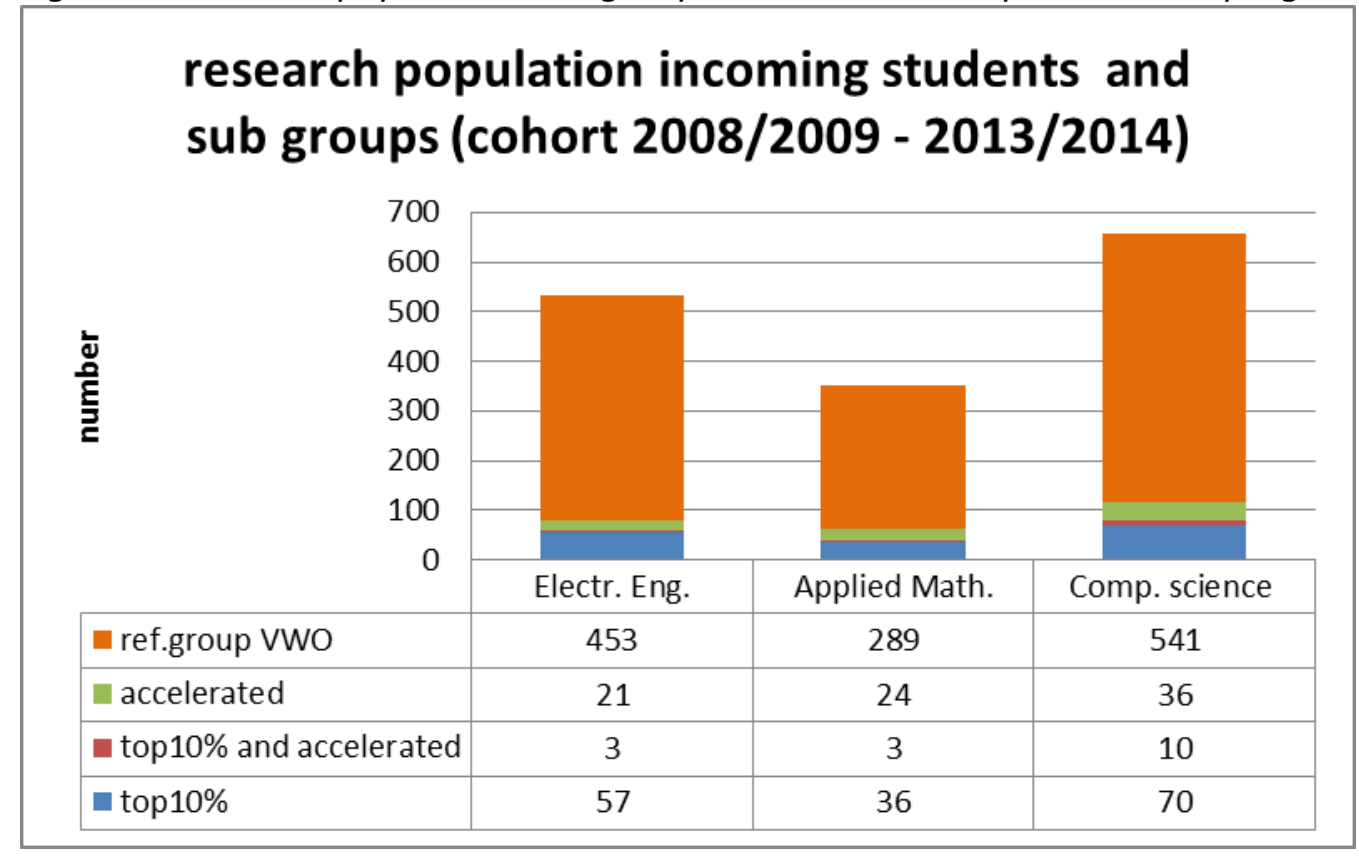

\section{Results}

The results show that the top ten percent students are somewhat younger than their study mates not belonging to the top ten percent. The early college entrants are mainly students that have skipped one class at primary or secondary education (17 years old); nine students were 16 years old and two students were 15 years old. The total research population has a number of 1543 students. The results of the student's performance in the first year confirm 
previous research about the relation to study success at universities of technology (Bogaard, 2015). Next to motivation a high GPA and high grades for maths and science courses in high school are good predictors for study success.

The performance of the top ten percent students in the regular bachelor programme is remarkably well, especially compared with students who did not belong to the top ten percent or the research group early college entrants. The dropout rate in the first year of regular programme from the 'top ten percent group' is about ten percent. About half (5\%) of the 'top group' decides to leave the programme within 0-4 months after the start. More than $60 \%$ of the top ten percent students complete their first year in one year and 30 to $40 \%$ do this with a GPA of 8 or higher. After three years $65 \%$ (or even more: $80 \%$ of the math students) completed their bachelor programme (cohorts 2008/2009-2012/13). About 40\% can do this with a GPA of 8 and higher and a 9 for the final bachelor thesis. The early college entrants did less well than the top ten percent, especially those students who enrolled in the computer science programme. The drop-out rate of this subgroup early college entrants in the first year is high (40\%); $30 \%$ of the early entrants students staying in the regular bachelor programme were successful in completing their regular programme in three years with a high GPA.

With regard to the choices these excellent students have made during their regular programme, it was found that $14 \%$ of the top ten percent group chooses to do an honours programme. These honours students all have Electrical Engineering or Computer Science as a major. The analysis also shows that gifted and talented students, instead of doing the honours programme, choose alternative extra activities, for example leading and management roles in study-, student- and civilian associations and special student projects, to broaden their skills. The TU Delft encourages students in these choices and gives them time and money to compensate for possible delay in their studies. It was remarkable that only few of the top ten percent from high school, who did not take an honours programme, has chosen to do extra courses next to their regular programme.

Additional research into the high school results from the students who have completed the honours programme showed that more than $50 \%$ of the selected and successful students, belong to the subgroup $30 \%$ to $10 \%$ of the best students from high school.

\section{Discussion and conclusions}

The results, shortly described here, give reason to collect more and also qualitative information about the performance and choices of ambitious and talented students. The research results also give insight into the quality of the incoming students and awareness of the possibilities to offer cognitively gifted students extra challenging study tasks in the regular programme as we do in the honours programme.

The results of this research and research into the background of the students doing an extra honours programme, have been input for restructuring the actual honours programme. We want to encourage more students to complete the extra honours programme. The high quality of incoming students and the small percentage of students choosing an extra honours programme in the second year, was reason to offer an interdisciplinary honours programme in the Robotics domain to excellent and motivated students already in the first year. It was also decided, due to the results that students choosing for an extra honours programme belong to the top $30 \%$ from high school, to monitor their study progress and 
results of this top $30 \%$ students and offer these students an extra training in metacognitive skills and to inform these students earlier about the possibilities to do an extra honours programme.

\section{References}

Bogaard, M.E.D. van den. (2015). Towards an action oriented model for first year engineering success. A mixed methods approach. Dissertation. TU Delft, Delft, Nederland. doi:10.4233/uuid:7e3ea63e-3f28-4f9d-a340-95acc8828763

Gagné, F. (2009). Talent development as seen through the differentiated model of giftedness and talent. In T. Balchin, B. Hymer, \& D. J. Matthews (Eds.), The Routledge International Companion to Gifted Education (pp. 32-42). New York: Routledge.

Mendaglio, S. (2013). Gifted students' transition to university. Gifted Education International, 29(1), 3-12.

Veenman, M. V., Bavelaar, L., De Wolf, L., \& Van Haaren, M. G. (2014). The on-line assessment of metacognitive skills in a computerized learning environment. Learning and Individual Differences, 29, 123-130. 